\title{
sciendo
}

\section{Research on dose correction method of vehicle-borne environmental radiation measurement equipment}

Jie Xu, Jizhou Ren, Jianbo Yang $\mathbb{B}$, Jiawen Fan,

Rui Li,

Hui Li,

Weiqi Huang, Biao Yuan

\begin{abstract}
This study establishes a near-ground reference radiation field based on typical radionuclides of the Fukushima accident in response to the need for vehicle-borne environmental radiation measurement equipment that can accurately evaluate the environmental dose of nuclear accidents. The Monte Carlo code FLUKA is used to study the environmental dose of such equipment in the early and mid-late reference radiation fields of nuclear accidents. Results of the air dose rate at $1 \mathrm{~m}$ above the ground were corrected to eliminate data difference between diverse measurement platforms. Simulation results show that the dose correction factor (CF) fluctuates at approximately 0.8813 in the early reference radiation field and at approximately 0.6711 in the mid-late reference radiation field. This deviation of the dose CF in the early and mid-late reference radiation fields is within $2 \%$ and is not affected by the change in detector position. This research can be applied to obtain more accurate measurement of an ambient dose in the near-ground radiation field and support the vehicle-borne environmental radiation measurement technology.
\end{abstract}

Keywords: Dose correction factor • Reference radiation field • Vehicle-borne environmental radiation measurement equipment

J. Xu, J. Z. Ren ${ }^{\bowtie}$, J. W. Fan, R. Li, H. Li

Chengdu University of Technology

Chengdu 610059, China

E-mail: 15661584@qq.com

J. B. Yang

Chengdu University of Technology

Chengdu 610059, China

and Sichuan University of Science and Engineering

Zigong 643000, China

W. Q. Huang, B. Yuan

Army Chemical Defense Academy

Beijing 102205, China

Received: 8 December 2020

Accepted: 10 June 2021

\section{Introduction}

The Fukushima accident in Japan in March 2011 caused severe radioactive nuclear leakage and spread to surrounding areas, which had a large-scale impact on the environment in a short period of time $[1,2]$. An important measurement and the key to ensuring quality in the environmental radiation monitoring of nuclear accidents is the gamma radiation dose rate of the ambient surface [3]. The most commonly used technical monitoring is vehicle-borne environmental radiation measurement equipment due to its high mobility, rapid response, and the ability to obtain the distribution data of the environmental radiation field.

Since the beginning of the 1980s, developed countries such as the United States, Canada, and Japan have successfully developed vehicle-borne large-volume NaI gamma spectrometer detection systems for environmental radiation monitoring, nuclear accident emergency, and radioactive source detection $[4,5]$. In recent years, China's environmental protection departments have actively conducted capacity building in environmental radiation monitoring. Domestic enterprises have also developed and produced a number of vehicle-borne radiation detection systems to assess the ambient dose rate and the dose rates of detected gamma-emitting

0029-5922 @ 2021 The Author(s). Published by the Institute of Nuclear Chemistry and Technology.

This is an open access article under the CC BY-NC-ND 4.0 licence (http://creativecommons.org/licences/by-nc-nd/4.0/). 
nuclides. In 2007, the Ministry of Environmental Protection issued the "National standards for the construction of radiation environmental monitoring and supervision institutions", which included the vehicle-borne radioactive detection system as the configuration object [6].

After the Fukushima nuclear accident in Japan, the stationary station nearby was destroyed by tsunami and other natural disasters. Thus, the vehicle-borne environmental radiation measurement equipment has a crucial role in environmental dose rate monitoring. The measurement principle of this equipment is similar to that of the stationary station. The difference is that the former has a strong mobile performance than the latter.

Vehicle-borne radiation detection system has been used to measure environmental dose rate [6, 7]. However, the use of this system for accurate monitoring of the environment and radioactive material radiation dose remains a difficult problem. The use of different measurements for the environmental dose value of a point can lead to inconsistent or even widely different results. At present, China has not released the relevant standards and technical specifications for the dose calibration of a vehicle-borne spectrometer. This study presents a new method to accurately calculate the surface environmental dose using vehicle-borne radiation measuring equipment. A near-ground reference radiation field is built on the basis of the typical radionuclides of the Fukushima nuclear accident. The Monte Carlo code FLUKA is used to simulate the ambient dose under different reference radiation fields. All simulated results are converted into air dose $1 \mathrm{~m}$ above the ground surface, as required by the International Commission on Radiological Protection (ICRP 1996) [8], to establish the dose correction factor (CF) for the vehicle-borne radiation environment measurement equipment.

\section{Simulation methods and model construction}

The FLUKA code [9] is used to simulate the environmental dose of vehicle-borne environmental radiation measurement equipment in the reference radiation fields. The incident gamma photons interact with the scintillator material in large-volume detectors, and part of the energy of gamma photons is deposited in the detector. The energy of gamma rays deposited in $\mathrm{NaI}(\mathrm{Tl})$ crystals is recorded using the USRTRACK card and converted into dose rate. The activity of each nuclide is $1 \mathrm{Ci}$ at the initial time of all simulation data, and the simulation platform is Dell Server Precision T7920, CPU: Intel(R) Core (TM) i7-9750H @ 2.6 GHz, RAM 64.0 GB.

\section{Model construction of vehicle-borne radiation environment measurement equipment}

Vehicle-borne environmental radiation measurement technology measures the type and content of radionuclides on the ground and the air-absorbed

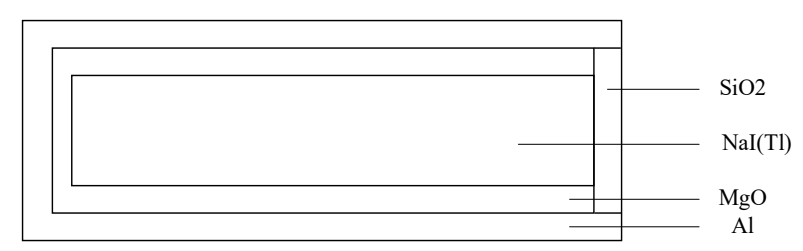

Fig. 1. NaI (Tl) detector model.

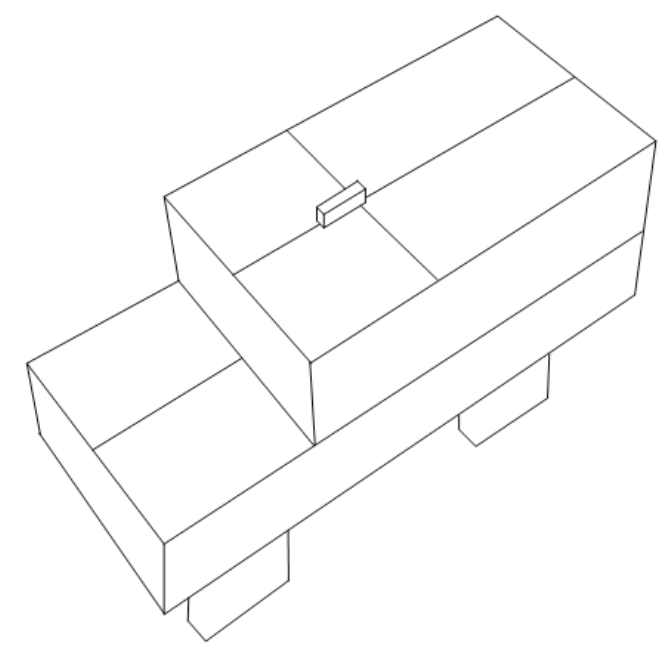

Fig. 2. Simulation model of vehicle-borne radiation environmental measurement equipment.

dose rates along the road using the gamma spectrometer mounted on a car [4]. The Monte Carlo code FLUKA is used to simulate the ambient dose rate of vehicle-borne environmental radiation measurement equipment. A schematic of the FLUKA model used for simulations is illustrated in Figs. 1 and 2. The $4 \mathrm{~L} \mathrm{NaI}(\mathrm{Tl})$ crystal is covered by a 0.5 -mm-thick $\mathrm{MgO}$ reflector, which is surrounded by aluminium with a thickness of $2 \mathrm{~mm}$, and by a layer of $2-\mathrm{mm}$ -thick $\mathrm{SiO}_{2}$ on the photomultiplier coupling side. Given that NaI ( $\mathrm{Tl})$ crystals are susceptible to deliquescence, an aluminium box is used to seal them. The dry MgO powder between the crystal and the aluminium box acts as a reflective layer to reflect the light emitted in the scintillator in all directions to the crystal, and $\mathrm{SiO}_{2}$ can effectively transmit the light to the photomultiplier tube. The main component of the on-board radiation measurement equipment is a $4 \mathrm{~L} \mathrm{NaI}(\mathrm{Tl})$ detector mounted on the roof (in horizontal placement) of a Cheetah Land Cruiser LBA6482LQ4. The point source is assumed to emit $1.332 \mathrm{MeV}$ gamma rays, and the distance between the isotropic gamma-ray point source and the $10 \mathrm{~cm}$ $\times 10 \mathrm{~cm}$ surface of the $\mathrm{NaI}(\mathrm{Tl})$ crystal is $100 \mathrm{~cm}$. The intrinsic detection efficiency of a $\mathrm{NaI}$ detector is defined as the ratio of the number of pulses deposited in the $\mathrm{NaI}(\mathrm{Tl})$ crystal to the incident radiation source on the surface of the detector. The simulation shows that the intrinsic detection efficiency of $\mathrm{NaI}$ (Tl) for $1.332 \mathrm{MeV}$ gamma ray is $65.30 \%$.

The car body structure is simplified to improve the efficiency of simulation calculations. Except for the chassis and tires, the car body adopts a box structure, while other scattered and lighter parts are ignored to simulate the real car to the maximum 
Table 1. Detailed information of the structure and materials of each component in the generalized model of vehicle-borne environmental radiation measurement equipment

\begin{tabular}{lcccc}
\hline \multicolumn{1}{c}{ Structure } & Material & Component & $\begin{array}{c}\text { Density } \\
\left(\mathrm{g} / \mathrm{cm}^{3}\right)\end{array}$ & $\begin{array}{c}\text { Thickness } \\
(\mathrm{cm})\end{array}$ \\
\hline Vehicle chassis & Alloy steel & $3.45 \% \mathrm{C}, 96.55 \% \mathrm{Fe}$ & 7.85 & 10.00 \\
Vehicle tires & Rubber & $11.84 \% \mathrm{H}, 88.16 \% \mathrm{C}$ & 0.92 & - \\
& Aluminium skin & $100 \% \mathrm{Al}$ & 2.70 & 0.12 \\
Carriage & Polyurethane foam & $54.4 \% \mathrm{C}, 12.1 \% \mathrm{~N}, 33.5 \% \mathrm{O}$ & 0.04 & - \\
& Glass & $46.0 \% \mathrm{O}, 33.6 \% \mathrm{Si}, 10.7 \% \mathrm{Ca}, 9.7 \% \mathrm{Na}$ & 2.40 & 1.00 \\
& Aluminium alloy & $97.43 \% \mathrm{Al}, 1.55 \% \mathrm{C}, 1.02 \% \mathrm{Cu}$ & 2.80 & 3.76 \\
& Sodium iodide & $15.34 \% \mathrm{Na}, 84.66 \% \mathrm{I}$ & 3.67 & - \\
Detector crystal & Magnesium oxide & $39.7 \% \mathrm{O}, 60.3 \% \mathrm{Mg}$ & 2.58 & 0.05 \\
& Aluminium & $100 \% \mathrm{Al}$ & 2.70 & 0.20 \\
& Silicon dioxide & $53.2 \% \mathrm{Si}, 46.8 \% \mathrm{O}$ & 2.32 & 0.20 \\
\hline
\end{tabular}

(a)

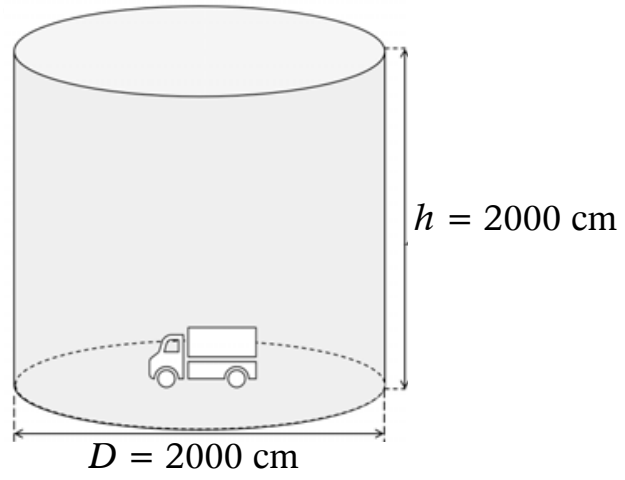

(b)

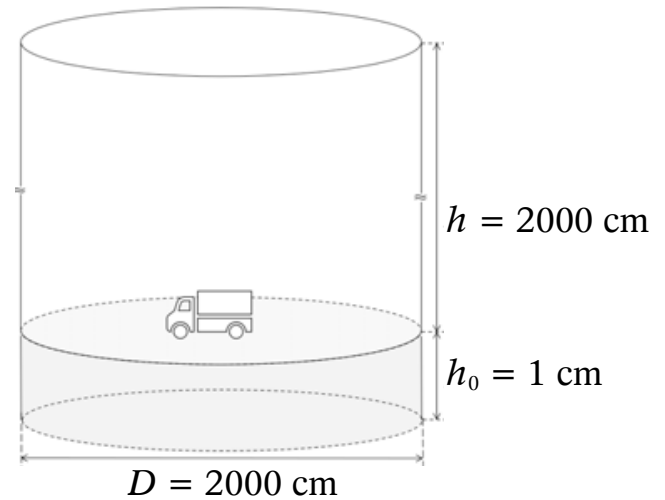

Fig. 3. Reference radiation field model: (a) early radiation field and (b) mid-late radiation field.

extent. Table 1 shows the detailed information, such as the structure and materials, of each component in the studied equipment.

\section{Construction of a near-ground reference radiation field model}

A nuclear accident produces a complex radiation field composed of hundreds of radionuclides with varying distributions over time $[10,11]$. Therefore, using the traditional ground radiation detection method is insufficient. In this study, the radiation field distribution in the radioactive source area of a nuclear accident is simulated using the Monte Carlo program by sampling the radiation rays and energy directions. According to the national standard GB/T17982-2018 [12], nuclear accidents are divided into time periods or phases: the early stage is the initial moment of decay (nuclear accident); the middle stage starts 1 day after the accident; and the later stage starts 100 days after the accident. The cylindrical source model is used to approximate the infinite radiation field after the nuclear accident, as shown in Fig. 3. In the early phase, radioactive substances are released into the atmosphere and dispersed in the air (Fig. 3a). These radionuclides are assumed to be uniformly distributed in the form of the plume. The cylinder has a radius of $1000 \mathrm{~cm}$ and a height of $2000 \mathrm{~cm}$. The entire space is filled with air, and the radiation field volume is $V=6280 \mathrm{~m}^{3}$.
In the mid-late nuclear phase of nuclear accidents, the radionuclides rapidly deposited in the soil after a nuclear accident, and the early radioactive materials are gradually deposited on the soil to form a radiation field of ground radioactive fallout (Fig. 3b). Similarly, the cylinder has a radius of $1000 \mathrm{~cm}$ and a height of $2000 \mathrm{~cm}$. The bottom of the column is filled with a 1-cm-thick layer of soil [13], and the air above this surface is used as an air model. The soil density [14] is $1.7 \mathrm{~g} / \mathrm{cm}^{3}$, and the soil mass is $M=4710 \mathrm{~kg}$. Table 2 shows the air and soil content.

\section{Source term analysis of radiation field}

The consequence assessment and environmental radiation monitoring of the Fukushima accident is a complex and arduous task, and the source item is an important basis for accident classification $[15,16]$. Numerous researchers of the Fukushima accident

Table 2. Mass fraction percentage of main components of air and soil

\begin{tabular}{ccccc}
\hline \multicolumn{5}{c}{ Air } \\
\hline $\mathrm{C}$ & $\mathrm{N}$ & $\mathrm{O}$ & $\mathrm{Ar}$ & \\
0.02 & 75.50 & 23.20 & 1.28 \\
\hline \multicolumn{5}{c}{ Soil } \\
\hline $\mathrm{H}$ & $\mathrm{O}$ & $\mathrm{Al}$ & $\mathrm{Si}$ & $\mathrm{Fe}$ \\
6.67 & 48.33 & 18.00 & 22.50 & 4.50 \\
\hline
\end{tabular}


Table 3. Representative nuclides in single-nuclide reference radiation field

\begin{tabular}{lccccc}
\hline Nuclides & ${ }^{60} \mathrm{Co}$ & ${ }^{132} \mathrm{Te}$ & ${ }^{137} \mathrm{Cs}$ & ${ }^{131} \mathrm{I}$ & ${ }^{133} \mathrm{Xe}$ \\
\hline Half-life & $5.27 \mathrm{a}$ & $76.80 \mathrm{~h}$ & $30.07 \mathrm{a}$ & $8.02 \mathrm{~d}$ & $5.25 \mathrm{~d}$ \\
Gamma energy $(\mathrm{keV})$ & $1173.24,1332.50$ & 228.16 & 661.66 & 364.49 & 81.00 \\
\hline
\end{tabular}

Table 4. Environmental background composition of the reference radiation field

\begin{tabular}{lcccccc}
\hline \multicolumn{1}{c}{ Distribution } & \multicolumn{2}{c}{ Aerosol } & \multicolumn{2}{c}{ Soil } \\
\hline Nuclides & ${ }^{7} \mathrm{Be}$ & ${ }^{40} \mathrm{~K}$ & ${ }^{137} \mathrm{Cs}$ & ${ }^{210} \mathrm{~Pb}$ & ${ }^{137} \mathrm{Cs}$ & ${ }^{226} \mathrm{Ra}$ \\
Energy (keV) & 477.61 & 1460.83 & 661.66 & 46.54 & 661.66 & 186.21 \\
Background $(\mathrm{Bq})$ & $5.66 \times 10^{1}$ & $2.36 \times 10^{0}$ & $1.37 \times 10^{-2}$ & $2.84 \times 10^{1}$ & $3.91 \times 10^{5}$ & $2.98 \times 10^{4}$ \\
\hline
\end{tabular}

assess the total amount of radioactive materials released into the atmosphere to evaluate the environmental impact [16-20]. However, in daily training, nuclear emergency equipment is used in a radiation field environment formed by a single nuclide. For this reason, this study specifically selects five representative radionuclides released after nuclear accidents (Table 3 ) as a single-nuclide reference to study the distribution of radiation fields in the early phases of nuclear accidents [16].

The Fukushima accident released various types of characteristic radionuclides. However, simultaneous analyses of the natural radionuclides in the environment are necessary considering the background effect. Table 4 shows the selected nuclides required for the background reference radiation field in the "2018 Annual Report of the National Radiation Environment" [21]. The aerosol activity is the air model for the early radiation field and the soil activity is the soil model for the mid-late stage. The complex radiation field distribution composed of hundreds of nuclides is affected by various factors, such as meteorological and geological conditions. The source term distribution of radiation field needs to be obtained from a specific time and location. Thus, this study uses the nuclide data during the Fukushima accident as the source term of the mixed reference radiation field.

Tables 5 and 6 include the main nuclides, radioactive concentration, and activity of the mixed reference radiation field in the early and middle phases of the Fukushima accident, respectively. The radioactivity calculation of the nuclides in the reference radiation fields is shown in Eqs. (1) and (2).

$$
\begin{aligned}
& A_{1}=C_{1} \times V \\
& A_{2}=C_{2} \times M
\end{aligned}
$$

where $A$ is the radionuclide activity, $C$ is the radionuclide concentration, 1 and 2 are the different reference radiation fields, $V$ is the volume of the early air reference radiation field, and $M$ is the mass of the mid-late soil reference radiation field.

\section{Vehicle-borne radiation system measurement}

When different measuring platforms are used to assess the ground deposition of nuclides, all measurement results must be corrected to maintain data consistency from the different material structures and placement height of the measuring instrument $[22,23]$. In this study, the detector is installed on the top of the car, parts of the ambient gamma rays are shielded by the body material, and the height attenuation caused by the detection equipment affects the measurement results. Therefore, CF needs to match the dose measured by the vehicle-borne radiation ambient measurement equipment with the air dose. The Monte Carlo simulation is used to study the air absorption dose rate detected by $\mathrm{NaI}$ (Tl) detection crystal at two positions inside and outside the vehicle. Thus, the dose CF is established, as shown in Eq. (3).

$$
\mathrm{CF}=\left(\frac{\dot{D}_{\text {car }}}{\dot{D}_{\text {air }}}\right)
$$

where CF is the dose CF of the measured dose in the vehicle-borne radiation measurement equipment and $\dot{D}_{\text {car }}$ and $\dot{D}_{\text {air }}$ are the air absorption dose rates measured by the detector mounted on the car roof in the car and $1 \mathrm{~m}$ above the ground in the air, respectively. Under the same conditions, the simulated detector is placed on the car roof at different dose rates to verify the dose $\mathrm{CF}$. In the end, the air dose rate at $1 \mathrm{~m}$ above the ground can be obtained by applying the dose attenuation CF to the vehicle-borne radiation dose measurement, as shown in Eq. (4).

$$
\dot{D}_{1 \mathrm{~m}}=\frac{\dot{D}_{\text {car }}}{\text { CF }}
$$

where $\dot{D}_{1 \mathrm{~m}}$ is the ambient dose rate at $1 \mathrm{~m}$ above the ground and $\dot{D}_{\text {car }}$ is the ambient dose rate measured by the vehicle-borne radiation measurement equipment.

\section{Results and discussion}

\section{Ambient dose rate of the single-nuclide reference radiation field}

The Monte Carlo program is used to simulate the dose rate of ${ }^{60} \mathrm{Co},{ }^{131} \mathrm{I},{ }^{132} \mathrm{Te},{ }^{133} \mathrm{Xe}$, and ${ }^{137} \mathrm{Cs}$ radionuclides with activity of $1 \mathrm{Ci}$ in the early reference radiation field, as shown in Fig. 4. The ambient dose rate increases exponentially with the increase in radionuclide energy in the single-nuclide reference radiation field. In determination radionuclide activity, the dose rate change is only related to nuclide energy. 


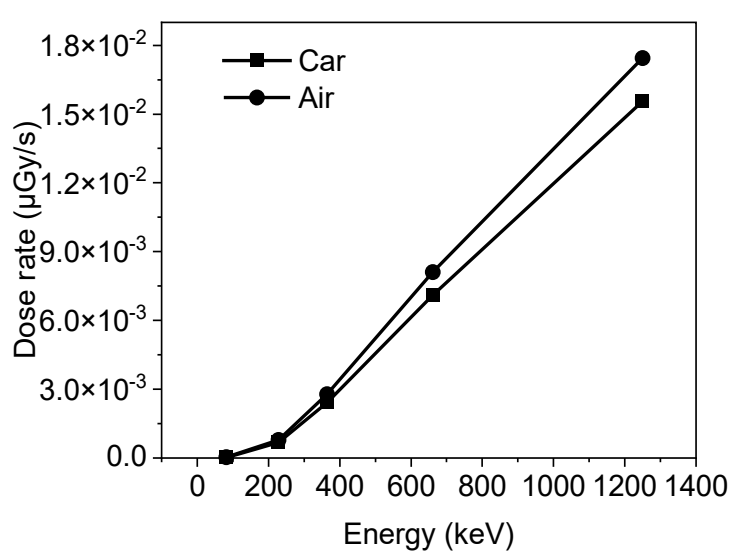

Fig. 4. Trend of ambient dose rate with gamma energy in the single reference radiation field.

Table 7. Dose rates measured at the height of $1 \mathrm{~m}$ above the ground and at the car roof of single-nuclide radiation field $(\mu \mathrm{Gy} / \mathrm{s})$

\begin{tabular}{lccc}
\hline Nuclides & $\begin{array}{c}\text { Energy } \\
(\mathrm{keV})\end{array}$ & $\begin{array}{c}\text { Car } \\
(\mu \mathrm{Gy} / \mathrm{s})\end{array}$ & $\begin{array}{c}\text { Air } \\
(\mu \mathrm{Gy} / \mathrm{s})\end{array}$ \\
\hline${ }^{133} \mathrm{Xe}$ & 81.00 & $2.5149 \times 10^{-5}$ & $2.8241 \times 10^{-5}$ \\
${ }^{132} \mathrm{Te}$ & 228.16 & $6.8513 \times 10^{-4}$ & $7.8970 \times 10^{-4}$ \\
${ }^{131} \mathrm{I}$ & 364.49 & $2.4188 \times 10^{-3}$ & $2.7888 \times 10^{-3}$ \\
${ }^{137} \mathrm{Cs}$ & 661.66 & $7.0965 \times 10^{-3}$ & $8.1073 \times 10^{-3}$ \\
${ }^{60} \mathrm{Co}$ & $1173.24,1332.501 .5559 \times 10^{-2}$ & $1.7436 \times 10^{-2}$ \\
\hline
\end{tabular}

Table 7 shows the ambient dose rates at the calibration locations. The rates range from $2.8 \times$ $10^{-5} \mu \mathrm{Gy} / \mathrm{s}$ to $1.7 \times 10^{-2} \mu \mathrm{Gy} / \mathrm{s}$ as measured at the height of $1 \mathrm{~m}$ above the ground, and the rates range from $2.5 \times 10^{-5} \mu \mathrm{Gy} / \mathrm{s}$ to $1.5 \times 10^{-2} \mu \mathrm{Gy} / \mathrm{s}$ as measured by the detector at the car roof. Under the same conditions, the trends of environmental dose rates detected by the NaI (Tl) detector inside and outside the vehicle are roughly the same. The dose rate measured outside is larger than that measured by the vehicle-borne detector because of the shielding effect of the vehicle and its contents.

\section{Ambient dose rate of mixed-nuclide reference radiation fields}

Tables 5 and 6 show various radionuclides and activity in the mixed-nuclide reference radiation fields. For the early phase of nuclear accidents, this study considers $2 \mathrm{~h}$ as the step length. For the mid-late stage, 100 days as a time node is used to calculate 12 different periods ( 1 day, $3,5,7,9,11,13$, $20,40,60,80$, and 100 days) to obtain the change curve of atomic number and activity of the radioactive decay progeny, as shown in Fig. 5. The radionuclide activity in two different reference fields decreases exponentially over time. The results show that these decreases are not related to the radiation field model but only related to the decay constant.

Figures $6 \mathrm{a}$ and $6 \mathrm{~b}$ show the trend of changes in the environmental dose rate measured by the $\mathrm{NaI}$ (Tl) detector inside and outside of the vehicle, respectively. In this study, the early reference radiation field is the air body source, and the air absorption 

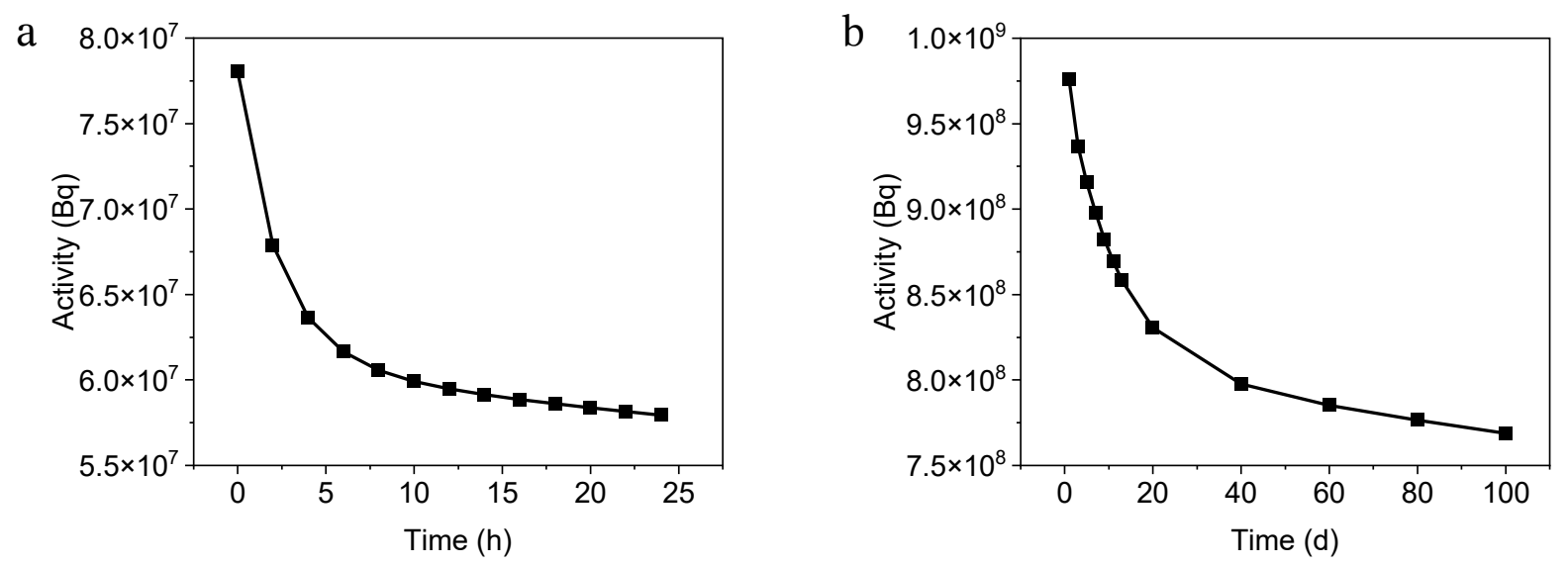

Fig. 5. Results of radionuclide activity over time: (a) early radiation field and (b) mid-late radiation field.
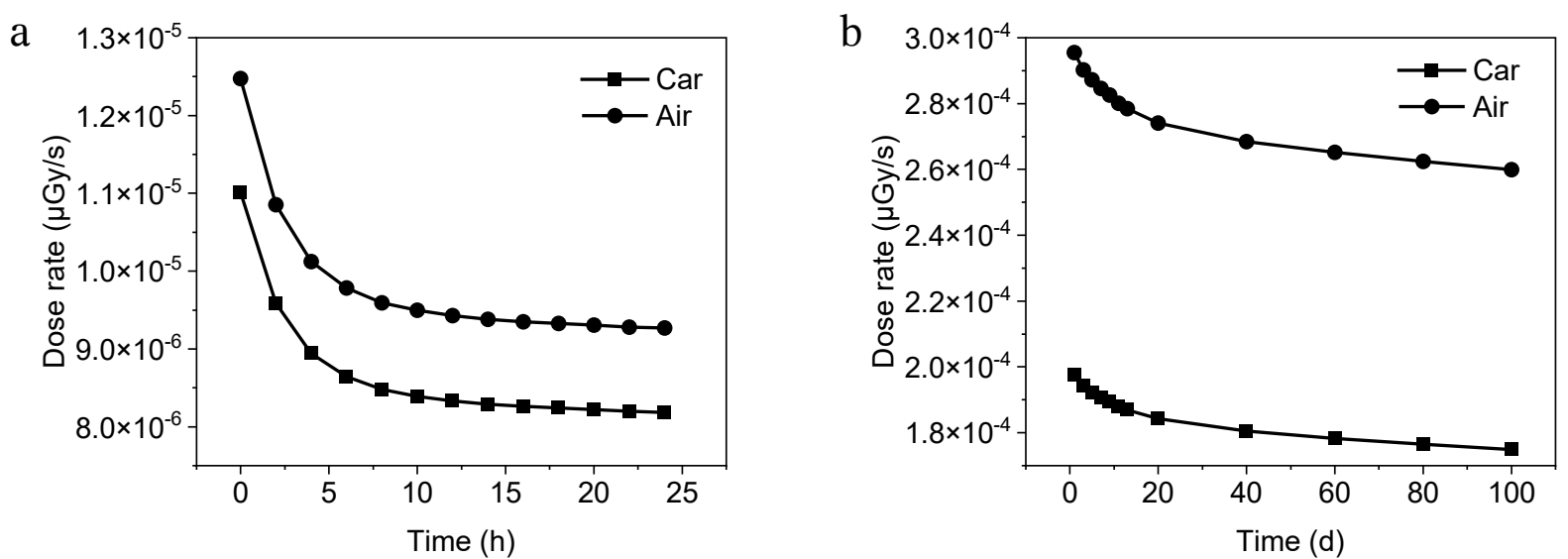

Fig. 6. Ambient dose rates of the mixed-nuclide radiation field varying with time: (a) early radiation field and (b) mid-late radiation field.

dose rate is evaluated to only consider the shielding effect of the car body. Thus, the dose rates inside and outside the vehicle slightly differ. By comparison, the mid-late reference radiation field is the soil body source, and the NaI ( $\mathrm{Tl})$ detector is placed on the roof, which essentially increases the source range. Thus, the $\mathrm{NaI}(\mathrm{Tl})$ detector receives a large difference in the ambient dose rate inside and outside the vehicle. The dose rate changes less and tends to flatten due to the long half-life and slow decay of certain radionuclides, such as ${ }^{137} \mathrm{Cs}$.

\section{Correction factor of the single-nuclide reference radiation field}

By convention, the ICRP 1996 [9] stipulates measurement of ambient dose rate at $1 \mathrm{~m}$ height to ensure consistent results when using different vehicle radiation measurement systems. In this study, only the shielding effect of the car body and the influence of the detector distance from the ground are considered to evaluate the air absorption dose rate. The CF of the vehicle-borne radiation environment measurement equipment under different radiation fields can be obtained using Eq. (3).

The ambient dose rate of the single-nuclide reference radiation field is simulated using the Monte Carlo program. Table 8 shows the results of the dose CF obtained by Eq. (3). The mean dose CF is 0.8786 ,
Table 8. Dose CF of single-nuclide reference radiation field

\begin{tabular}{lccccc}
\hline Nuclides & ${ }^{133} \mathrm{Xe}$ & ${ }^{132} \mathrm{Te}$ & ${ }^{131} \mathrm{I}$ & ${ }^{137} \mathrm{Cs}$ & ${ }^{60} \mathrm{Co}$ \\
\hline $\mathrm{CF}$ & 0.8905 & 0.8676 & 0.8673 & 0.8753 & 0.8923 \\
\hline
\end{tabular}

$\mathrm{CF}$, correction factor.

and the error is within $2 \%$. The results show that energy change negligibly affects the dose CF.

\section{Correction factor of the mixed-nuclide reference radiation field}

The dose CF of the mixed-nuclide reference radiation field using the vehicle-borne environmental radiation measurement equipment is listed in Tables 9 and 10 . The early reference field CF is regarded as a fixed value of 0.8830 , and the mid-late mixed-nuclide reference field dose CF fluctuates at approximately 0.6711 . The dose rate measured by the vehicle-borne equipment is applied to $1 \mathrm{~m}$ above the ground in air using Eq. (4).

\section{Effects of detector position}

The dose rate measurements are repeated at several locations with different ambient dose levels and detector installation locations to verify the validity of the dose CF. Table 11 shows the average results 
Table 9. Dose CF of early mixed-nuclide reference radiation field

\begin{tabular}{|c|c|c|c|c|c|c|c|c|c|c|c|c|c|}
\hline Time (h) & 0 & 2 & 4 & 6 & 8 & 10 & 12 & 14 & 16 & 18 & 20 & 22 & 24 \\
\hline $\mathrm{CF}$ & 0.883 & 0.883 & 0.883 & 0.884 & 0.884 & 0.884 & 0.884 & 0.884 & 0.884 & 0.884 & 0.884 & 0.883 & 0.883 \\
\hline
\end{tabular}

CF, correction factor.

Table 10. Dose CF of mid-late mixed-nuclide reference radiation field

\begin{tabular}{lcccccccccccc}
\hline Time (d) & 1 & 3 & 5 & 7 & 9 & 11 & 13 & 20 & 40 & 60 & 80 & 100 \\
\hline $\mathrm{CF}$ & 0.669 & 0.669 & 0.670 & 0.670 & 0.670 & 0.671 & 0.671 & 0.672 & 0.672 & 0.672 & 0.672 & 0.673 \\
\hline
\end{tabular}

Table 11. Detector located at different locations of the dose CF

\begin{tabular}{lcccc}
\hline \multicolumn{1}{c}{ Central place } & Car $(\mu \mathrm{Gy} / \mathrm{s})$ & Air $(\mu \mathrm{Gy} / \mathrm{s})$ & CF & Error \\
\hline $97.5,160,160$ & $7.0442 \times 10^{-3}$ & $7.8729 \times 10^{-3}$ & 0.8947 & $0.8813+0.015$ \\
$97.5,195,160$ & $7.0905 \times 10^{-3}$ & $7.9737 \times 10^{-3}$ & 0.8892 & $0.8813+0.009$ \\
$97.5,230,160$ & $7.0965 \times 10^{-3}$ & $8.1073 \times 10^{-3}$ & 0.8753 & $0.8813-0.007$ \\
$47.5,240,160$ & $7.0088 \times 10^{-3}$ & $8.0049 \times 10^{-3}$ & 0.8756 & $0.8813-0.006$ \\
$147.5,240,160$ & $7.0541 \times 10^{-3}$ & $8.0180 \times 10^{-3}$ & 0.8798 & $0.8813-0.002$ \\
$97.5,265,160$ & $7.1126 \times 10^{-3}$ & $8.1010 \times 10^{-3}$ & 0.8780 & $0.8813-0.004$ \\
$97.5,300,160$ & $6.8867 \times 10^{-3}$ & $7.8778 \times 10^{-3}$ & 0.8742 & $0.8813-0.008$ \\
$97.5,335,160$ & $7.1724 \times 10^{-3}$ & $8.2174 \times 10^{-3}$ & 0.8728 & $0.8813-0.010$ \\
$47.5,370,160$ & $7.0047 \times 10^{-3}$ & $7.9291 \times 10^{-3}$ & 0.8834 & $0.8813+0.002$ \\
$97.5,370,160$ & $6.9351 \times 10^{-3}$ & $7.8866 \times 10^{-3}$ & 0.8794 & $0.8813-0.002$ \\
$147.5,370,160$ & $7.2050 \times 10^{-3}$ & $8.1576 \times 10^{-3}$ & 0.8832 & $0.8813+0.002$ \\
$97.5,405,160$ & $6.9543 \times 10^{-3}$ & $7.8149 \times 10^{-3}$ & 0.8899 & $0.8813+0.010$ \\
\hline
\end{tabular}

$\mathrm{CF}$, correction factor.

of the detector placed at different positions. The data are divided into dose rate and CF according to Eq. (3).

\section{Conclusion}

This study establishes a near-ground reference radiation field based on typical radionuclides of the Fukushima accident as the source term data. The Monte Carlo program simulation is used to study the environmental dose of vehicle-borne environmental radiation measurement system. The dose CF is established by simulating the ambient dose rate of the Cheetah Land Cruiser LBA6482LQ4 with a $4 \mathrm{~L} \mathrm{NaI} \mathrm{(Tl)} \mathrm{detector} \mathrm{in} \mathrm{the} \mathrm{early} \mathrm{and} \mathrm{mid-late}$ reference radiation fields of nuclear accidents. The main conclusions are as follows:

1. In the early reference radiation field, the radionuclides are uniformly distributed in the air, the ambient dose rate is only related to the vehicle material structure, and the average dose CF is 0.8813 .

2 . In the mid-late reference radiation field, the ambient dose rate is highly correlated with the body material structure and the height of the detector from the surface under the assumption that radionuclides all sank to the surface to form soil body source. The average value of the environmental dose CF is 0.6711 .
3. The results of the ambient dose CF are independent of the detector position, but this case is only in the established reference radiation field.

This paper presents the study of the dose correction method for the monitoring process. The dynamic measurement of this process will be presented in a subsequent paper.

Acknowledgments. This work was supported by the National Natural Science Foundation of China (no. 41774120) and the Sichuan Science and Technology Program (no. 2021YJ0329).

\section{ORCID}

Y. B. Yang (D) http://orcid.org/0000-0001-8429-5018

\section{References}

1. Kinase, S., Takahashi, T., \& Saito, K. (2017). Longterm predictions of ambient dose equivalent rates after the Fukushima Daiichi nuclear power plant accident. J. Nucl. Sci. Technol., 54(12), 1345-1354. DOI: 10.1080/00223131.2017.1365659.

2. Franić, Z., Branica, G., Petrinec, B., \& Marović, G. (2020). Long-term investigation of ${ }^{137} \mathrm{Cs}$ and ${ }^{134} \mathrm{Cs}$ 
in drinking water in the city of Zagreb, Croatia. Nukleonika, 65(3),193-198. DOI: 10.2478/nuka2020-0030.

3. Lee, U., Bae, J. W., \& Kim, H. R. (2017). Environmental gamma radiation analysis for Ulsan city with the highest nuclear power plant density in Korea. $J$. Environ. Radioact., 178, 177-185. DOI: 10.1016/j. jenvrad.2017.08.015.

4. Gong, P., Tang, X. B., Huang, X., Wang, P., Wen, L. S., Zhu, X. X., \& Zhou, C. (2019). Locating lost radioactive sources using a UAV radiation monitoring system. Appl. Radiat. Isot., 150, 1-13. DOI: 10.1016/j.apradiso.2019.04.037.

5. Aage, H. K., \& Korsbech, U. (2003). Search for lost or orphan radioactive sources based on $\mathrm{NaI}$ gamma spectrometry. Appl. Radiat. Isot., 58(1), 103-113. DOI: 10.1016/S0969-8043(02)00222-1.

6. Lu, X. J., Xin, Z. W., Song, J. B., Li, X. S., Han, G., \& Tang, D. F. (2019). Discussion on performance and detection method of car-borne radioactive detection system. Shanghai Meas. Test., 46(01), 35-37 (in Chinese).

7. Zhao, S. P., Yang, B., \& Song, J. F. (2012). Application of large volume $\mathrm{NaI}$ spectrometer in environmental monitoring. In Radiation Protection Society, 17 September 2012 (pp. 204-212). Hangzhou, China: Chinese Nuclear Society (in Chinese).

8. International Commission on Radiological Protection. (1996). Conversion coefficients for use in radiological protection against external radiation. (ICRP Publication 74). Ann. ICRP, 28(3/4).

9. Ferrari, A., Sala, P. R., \& Ranft, J. (2005). FLUKA: A Multi-Particle Transport Code. (CERN-2005-10 INFN/TC 05/11, SLAC-R-773 ).

10. Lu, X. S., Luo, P. A., Wang, Y. X., \& Li, X. B. (2002). Calculation of radioactive field in nuclear contaminated area from data acquired in aerial survey. $J$. Hunan Environ. Biol. Polytech., 8(04), 241-246 (in Chinese).

11. Saito, K., Mikami, S., Andoh, M., Matsuda, N., Kinase, S., Tsuda, S., Sato, T., Seki, A., Sanada, Y., Wainwright-Murakami, H., Yoshimura, K., Takemiya, H., Kato, H., \& Onda, Y. (2019). Temporal change in radiological environments on land after the $\mathrm{Fu}-$ kushima Daiichi nuclear power plant accident. $J$. Radiat. Prot. Res., 44(4), 128-148. DOI: 10.14407/ jrpr.2019.44.4.128.

12. National Health Commission of the People's Republic of China. (2018). Models and parameters for calculating radiation dose to the public in the emergency of a nuclear accident. China: Standardization Administration of China (in Chinese).

13. Xu, J. H., Wang, L., Wang, Y. C., Zhao, Z. S., \& Han, W. T. (2019). Remote sensing monitoring of soil surface moisture content based on LM algorithm. Trans. Chin. Soc. Agic. Mach., 50(06), 233-240 (in Chinese).

14. Lin, M. L., Wang, H., \& Li, X. B. (2002). $\gamma$ Energy spectra and direction distribution over area contaminated. Nucl. Electron. Detect. Tech., 22(04), 354-356 (in Chinese).

15. Lipka, M. (2020). Source term estimation for the MARIA research reactor and model of atmospheric dispersion of radionuclides with dry deposition. Nukleonika, 65(3), 173-179. DOI: 10.2478/nuka2020-0028.

16. Terada, H., Nagai, H., Tsuduki, K., Furuno, A., Kadowaki, M., \& Kakefuda, T. (2020). Refinement of source term and atmospheric dispersion simulations of radionuclides during the Fukushima Daiichi Nuclear Power Station accident. J. Environ. Radioact., 213, 106104. DOI: 10.1016/j.jenvrad.2019.106104.

17. Du Bois, P. B., Garreau, P., Laguionie, P., \& Korsakissok, I. (2014). Comparison between modelling and measurement of marine dispersion, environmental half-time and ${ }^{137} \mathrm{Cs}$ inventories after the Fukushima Daiichi accident. Ocean Dynamics, 64(3), 361-383. DOI: $10.1007 / \mathrm{s} 10236-013-0682-5$.

18. Cervone, G., \& Franzese, P. (2014). Source term estimation for the 2011 Fukushima nuclear accident. In G. Cervone, J. Lin \& N. Waters (Eds.), Data mining for geoinformatics: Methods and applications (pp. 49-64). New York: Springer Science+Business Media.

19. Koo, Y. H., Yang, Y. S., \& Song, K. W. (2014). Radioactivity release from the Fukushima accident and its consequences: A review. Prog. Nucl. Energy, 74, 61-70. DOI: 10.1016/j.pnucene.2014.02.013.

20. Lin, W., Chen, L., Yu, W., Ma, H., Zeng, Z., Lin, J., \& Zeng, S. (2015). Radioactivity impacts of the Fukushima nuclear accident on the atmosphere. Atmos. Environ., 102, 311-322. DOI: 10.1016/j. atmosenv.2014.11.047

21. Ministry of Ecological Environment. (2018). Annual Report of the National Radiation Environment. Retrieved June 13, 2019, from P020190614334254775343. pdf (mee.gov.cn) (in Chinese).

22. Young-Yong, J. I., Chung, K. H., \& Kang, M. J. (2020). Assessment of dose rate of detected gamma emitting nuclides using a carborne survey with a large volume NaI (Tl) detector. Prog. Nucl. Energy, 123, 103272. DOI: 10.1016/j.pnucene.2020.103272.

23. Takeishi, M., Shibamichi, M., Malins, A., Kurikami, H., Murakami, M., Saegusa, J., \& Yoneya, M. (2017). Using two detectors concurrently to monitor ambient dose equivalent rates in vehicle surveys of radiocesium contaminated land. J. Environ. Radioact., 177, 1-12. DOI: 10.1016/j.jenvrad.2017.05.010. 